\title{
Social Skills Training in Chronically Mentally Ill Patients under Psychosocial Rehabilitation
}

\author{
Olga Velentza ${ }^{1}$ \\ University of Athens
}

\begin{abstract}
Social skills training is a process that resembles the nursing process and its stages. It is one of the many social rehabilitation programs for chronic mental patients. It is also a process by which a health practitioner tries to diversify the existing state of chronic mental patients. It is a "set of cognitive-behavioral methods of social rehabilitation, which in a direct and active education, enhance and promote existing social skills. Alternatively, teaching new skills in chronic psychotic patients enables them to cope with the everyday demands of life, one the one hand, and to be protected from any symptoms of disease deterioration, on the other." The purpose of this study is for mental health professionals to learn and to teach ways of communication, behaviors, and socialization between chronically mentally ill patients and other people, as well as to enhance their capacity for independent life in the community. Social skills training, tailored to a patient's individual needs can help the patient to: (a) Develop and maintain personal relationships with other individuals, (b) take responsibility for medication, (c) find and maintain stable employment, (d) find and maintain permanent housing, ability to choose his/her preferred mode of recreation, and the opportunity to enjoy spare time, and (e) Maintain a level of functionality that enables the patient to live within a community and provides him/her with a minimum level of social skills, thereby enhancing his/her quality of life.
\end{abstract}

Keywords

Social skills $\bullet$ Chronic psychotic $\bullet$ Social skills training $\bullet$ Rehabilitation $\bullet$ Training methods

1 Correspondence to: Olga Velentza, Psychiatric Nurse R.N. Aiginiteio Hospital National and Kapodistrian University of Athens, Greece. Email:olyvelen@gmail.com

Citation: Velentza, O. (2016). Social skills training in chronically mentally Ill patients under psychosocial rehabilitation. Sanitas Magisterium, 2, 71-79. http://dx.doi.org/10.12738/SM.2016.1.0019 
Chronic psychotic patients, in addition to experiencing psychopathological symptoms, also face a gradual reduction of functionality and ability to participate in everyday life roles. In this significantly contributes the lack or limitation of skills in one or more areas such as the motor, the mental, the perceptual, activities of everyday life as well as work, social and emotional field (Karidi, 2007).

The main goal of rehabilitation for a psychotic patient is to achieve a healthy balance of roles by developing skills that will allow him to function at a satisfactory level in his personal and interpersonal life. To achieve these goals using the social activity which is the main therapeutic means of a therapist (Koukourikos, Tsormatzoudi, \& Tzogani, 2007; Ragia, 2009). Social activities are those skills that are learned and that are related with the improvement of one's social behavior and interpersonal interactions. Since these skills are learned, they can therefore be taught.

The gradual decline of social skills may be due to:

- Lack of standards.

- Lack of learning opportunities.

- Poor guidance.

- The existence of a significant disease or disability, or of emotional difficulties.

A deficit in social skills may in turn lead to the further development of social and/or psychological problems. Social skills training is a process by which a health practitioner attempts to diversify the existing condition of a mentally ill individual.

Social skills training is an organized educational process that gives particular importance to:

- The planning and implementation of social skills training programs.

- The interpretation of everyday roles, usually followed by feedback.

- The support of acquired social skills and attitudes.

Whether appropriate activities are applied or not is a major factor in provoking improvement and positive changes in mentally ill behavior. The correct choice of appropriate activities is based on analysis of characteristics and in combination with the individual's needs. The activities most commonly used are selected based on the functional and patient's personal needs. These activities can be either individual or collective. Also, the activities determined by the structure, philosophy and objectives of the framework in which rehabilitation services are provided (Kandilis, 1993; Koukourikos et al., 2007; Tsiantis \& Manolopoulos, 1998). 


\section{Field Exercise of Social Skills in Chronic Psychotic Patients}

The aim of training in issues related to chronic psychotic patients is to improve practitioners' knowledge and social skills in the following areas of functioning.

\begin{tabular}{ll}
\hline $\begin{array}{l}\text { Hygiene and personal } \\
\text { appearance }\end{array}$ & Refers mainly to residual patients \\
\hline Education in medication & $\begin{array}{l}\text { Aims to make the patient take responsibility in managing his medication and in } \\
\text { being able to cope with side effects }\end{array}$ \\
\hline Management leisure & $\begin{array}{l}\text { Aims for the patient to acquire the ability to choose activities and places that will } \\
\text { bring him/her joy and satisfaction }\end{array}$ \\
\hline $\begin{array}{l}\text { Learning of basic } \\
\text { conversation skills }\end{array}$ & $\begin{array}{l}\text { Involves teaching a patient the necessary social skills that will enable him/her to } \\
\text { start, continue, and complete a conversation }\end{array}$ \\
\hline Symptoms control & $\begin{array}{l}\text { Teaching a patient how to reduce symptoms' intensity and avoid being annoyed } \\
\text { by them }\end{array}$ \\
\hline Also taught & $\begin{array}{l}\text { The ability to recognize symptoms of an approaching crisis } \\
\text { The ability to seek help }\end{array}$ \\
\hline
\end{tabular}

(Karidi, 2007; Wilkinson \& Canter, 1991)

\section{Training Methods}

Social skills training is a process divided into smaller steps, starting with the easiest and most simple step and gradually progressing upward to more complex and difficult steps. For each step, instructions and explanations are provided and are then followed by a demonstration.

After the demonstration, the patient is asked to demonstrate the skill by representing a behavior, for which s/he receives feedback. Once the skill has been successfully acquired, it is then implemented in the patient's living environment.

\section{Guidance}

The instructor initially describes the behaviors to be taught and explains their significance and importance in daily practice. Instruction should be given in a simple and understandable language supplemented with many examples.

\section{Model Demonstration}

A chronically mentally ill patient has difficulty understanding and imitating behaviors taught only by means of verbal explanation. As such, it is necessary to for the instructor or a staff members demonstrate the desired behavior.

\section{Representing the Behavior}

Representing a behavior is among the key elements of successful social skill training. The challenge in this process is for the patient to be himself and to react as 
he would in daily life. Different responses to a behavior and experiences will enable the patient to form the basis for a change in his/her "social skills." The patient should be encouraged by the trainer both verbally and by example.

\section{Strengthen}

Social relations, which manifest as feedback or reward, are molded and fixed during the training process.

\section{Feedback}

Feedback a process by which a patient comes to realize and understand the outcome of his/her behavior. During this process, the patient participates actively, expressing his/her views or objections. Feedback should focus on the behavior and not on the patient's person, and should focus on positive aspects.

\section{Rewards}

Rewards are the most efficient form reinforcement and should be done through praise and encouragement. Their effectiveness is greater when administered immediately after the representation of a behavior.

Just as goals should be realistic, in-line with the patient's everyday life, and within the patient's capacities, so should they neither be too general in their description or formulated in behavioral terms. The objectives should be ordered by difficulty and should be sufficiently detailed (Bellack, Turner, Hersen, \& Luber, 1984; Granholm et al., 2005; Koukourikos et al., 2007).

\section{Program Design}

The design and development of social skills training programs should be based on individuals' real needs. These needs arise from the assessment of the patient's problems mainly through the interview itself, from input by the patient's relatives, friends, or other health professionals. After collecting information, what goals are hoped to be achieved should be identified and it should be determined as to whether the individual's education should be done individually or in a group setting.

\section{Individual Education}

$\checkmark$ Allows one to focus on specific individual problems.

$\checkmark$ Is preferable for anxious, phobic, and shy people.

$\checkmark$ Ensures the exclusive attention of the instructor. 


\section{Group education offers the following advantages:}

$\checkmark$ The group is a miniature of the society in which one lives, thereby offering a venue for "real" interactions.

$\checkmark$ Provides the possibility of coming together with different types of people.

$\checkmark$ Offers greater intensity during feedback.

$\checkmark$ Creates a supportive environment.

$\checkmark$ Reduces negative feelings, such as shame.

$\checkmark$ Participants experience that they are not alone and that there are others in a similar position.

$\checkmark$ There may be members in the group who have already gone through the education process and whose situation has improved. These members may set an example for others in the group

$\checkmark$ Allows optimal usage of trainers' time (Bellack, 2004; Bustillo, Lauriello, Horan, \& Keith, 2001; Karidi, 2007).

\section{Types of Programs}

The choice of program to be applied to an individual is based exclusively on that individual's specific needs, difficulties, and peculiarities. There are two types of training programs, personalized and standardized. Both of these types use the same training methods.

Individualized programs, which focus on dealing with the person's difficulties and on achieving specific targets, are organized in collaboration with the therapist.

In each session, some of the difficulties are dealt with in a step-by-step process, progressing from the simpler to the more complex steps.

The standard program is a structured series of courses that aim to improve or to retrain social skills, starting from the simplest behavior and progressing to the most complex.

The content of these programs depends on:

$\checkmark$ The type of population.

$\checkmark$ The designated purpose.

Standard programs are best used in a group setting than in individual training. 
The advantages of standardized programs are as follows:

$\checkmark$ The application is simpler in groups than in individuals.

$\checkmark$ The education provided by therapist is easier to grasp.

$\checkmark$ They benefit a large number of clients simultaneously.

$\checkmark$ They still a sense of security in members.

The disadvantages include the following:

$\checkmark$ There is the probability of not covering all members' needs in a satisfactory manner.

$\checkmark$ They are not always practical, especially in round robin cases.

In practice, these programs are usually combined. For example, the first part of a program consists of general education that is then followed by individualized work in subsequent sessions. The point is that programs should be flexible and taught by a therapist sensitive to his/her patients' needs (Koukourikos et al., 2007; Liberman, 1982; Presly, Grubb, \& Semple, 1982; Wallace \& Liberman, 1985)

\section{Handling of the Educational Process}

Patient preparing. The therapist's aim before the beginning of the process is three-fold: (1) to make the goals absolutely clear to the patient, (2) to describe the form that the process will take, and (3) to define what the patient should expect to achieve upon completing the program. The level and the details of the explanation should be adjusted to fit each individual patient's level of understanding and done so without using scientific terms.

There is a need for precision in time, regular monitoring, and full cooperation. For patients suffering from chronic psychotic illnesses, not only should there be a plan of mobilization that includes rewards for regular monitoring sessions, it should be known and understood by the patient.

If the patient is to participate in a group, s/he should be informed about the group's other participating members (Kopelowicz, Liberman, \& Zarate, 2006; Sylph, Ross, \& Kedwood, 1978).

The trainer. One quality that is necessary for a therapist to have is the ability to communicate. Through communication, a therapist will attempt to reach the patient, to know him/her, and to establish a relationship of trust, all of which are prerequisites for a successful therapy process. Although having knowledge of the subject is important, it is even more important that the instructor have experience, which he has obtained either by participation in educational groups or as an experienced instructor's assistant. 
In individual sessions, usually only one trainer is needed. In group sessions however, it is better to have a minimum of two trainers. Honesty should characterize the relationship between the two trainers themselves. Also, it is necessary them to know what their role in the session is.

Social skills training is a special, highly structured form of guidance education that requires on the one hand a careful definition of patients' problems, and on the other a detailed organization, and preparation of programs, from therapists.

A great deal more love, concern, and respect is needed when engaging with patients suffering from chronic psychotic illnesses (Baker \& Intagliata, 1982; Bellack, Hersen, \& Turner, 1976; Sullivan, Marder, Liberman, Donahoe, \& Mintz, 1990).

\section{Conclusion}

Acquiring social skills is a process that begins in childhood and progresses gradually. It is based on learning and imitation models. Equally important is environmental influence.

Activity as a therapeutic means helps significantly to trigger development and change in chronic psychotic patients. This to be effective requires the efficient and close cooperation of a multidisciplinary team. The basic knowledge of analysis and synthesis activity principles from the group members is necessary in order to be used a wide range of activities (Benton \& Schoeder, 1990; Hogarty et al., 1986; Spence \& Spence, 1980).

As a result of such therapeutic activities, a person:

$\checkmark$ Obtains information about his/her strengths and weaknesses in relation to practical skills, the influence of other people and events, and how to perceive reality.

$\checkmark$ Develops new skills or improves existing ones.

Improves physical, cognitive, and perceptual abilities.

$\checkmark$ Extends the range of roles that $\mathrm{s} / \mathrm{he}$ can undertake and acquires confidence in his/her ability to organize, control and fulfill goals.

$\checkmark$ Is able to express his/her feelings.

$\checkmark$ Is able to fulfill his/her physical and emotional needs.

$\checkmark$ Fosters communication skills.

Learns to set realistic goals (Eisler, 1978; Rimm, Hill, Brown, \& Stuart, 1974; Sood, Baker, \& Bledin, 1996). 
The importance of social skills training is that in addition to improving patients' functionality, it also helps to reduce relapses, re-hospitalization, and emotional stress in one's family.

As a result, patients are able to experience their most fundamental human right: the ability to choose to live as a responsible citizen with rights and obligations, gradually setting up a life plan. The user of health services is a person who does not represent a disease, but one suffers from a disease (Liberman et al., 1984; Smith et al., 1996).

\section{Epilogue}

As rehabilitation is defined the continuous process that begins with the diagnosis of disease and continues until the final positioning of the individual to a work with the appropriate living conditions. As part of the rehabilitation process, patients' active and constant participation are of prime importance.

Psychological rehabilitation aims to endow people with mental difficulties the opportunity to use physical, social, and cognitive resources to live and work with the least possible amount of outside care and support.

\section{References}

Baker, F., \& Intagliata, J. (1982). Quality of life in the evaluation of community support systems. Evaluation and Program Planning, 5, 62-79.

Bellack, A. S. (2004). Skills training for people with severe mental illness. Psychiatric Rehabilitation Journal, 27, 375-391.

Bellack, A. S., Hersen, M., \& Turner, S. M. (1976). Generalization effects of social skills training in chronic schizophrenics: An experimental analysis. Behaviour Research and Therapy, 14, 391-398.

Bellack, A. S., Turner, S. M., Hersen, M., \& Luber, R. F. (1984). An examination of the efficacy of social skills training for chronic schizophrenic patient. Hospital \& Community Psychiatry, 35, 1023-1028.

Benton, M., \& Schoeder, H. (1990). Social skills training with schizophrenics: A meta-analytic evaluation. Journal of Consulting and Clinical Psychology, 58, 741-747.

Bustillo, J. R., Lauriello, J., Horan, W. P., \& Keith, S. J. (2001). The psychosocial treatment of schizophrenia: An update. American Journal of Psychiatry, 158(2), 163-175.

Eisler, R. M. (1978). Social skill training with or without modeling of schizophrenic and nonpsychotic hospitalized psychiatric patients. Behavior Modification, 2, 147-172.

Granholm, E., McQuaid, J. R., McClure, F. S., Auslander, L. A., Perivoliotis, D., Pedrelli, P. ... Jeste, D. V. (2005). A randomized controlled trial of cognitive behavioral socials skills training for middle-aged and older outpatients with chronic schizophrenia. American Journal of Psychiatry, 162, 520-529.

Hogarty, G. E., Anderson, C. M., Reiss, D. J., Kornblith, S. J., Greenwald, D. P., Ulrich, R. F., \& Carter, M. (1986). Family psychoeducation, social skills training in the aftercare treatment of schizophrenia. Archives of General Psychiatry, 43, 633-642. 
Kandilis, D. (1993). The homecoming. From asylum Leros society of Larissa versions hours. Volos, 1993, 18-20.

Karidi, M. V. (2007). Elements of psychosocial approach to vocational rehabilitation of psychotic patients. Athens, Greece: Publications Greek Letters.

Kopelowicz, A., Liberman, R. P., \& Zarate, R. (2006). Recent advances in social skills training for schizophrenia. Schizophrenia Bulletin, 32(Supp 1), S12-S33.

Koukourikos, K., Tsormatzoudi, E., \& Tzogani, A. (2007). Social rehabilitation-training social skills chronic psychotic patients. Nursing, 46(3), 342-354.

Liberman, R. (1982). Assessment of social skills. Schizophrenia Bulletin, 8, 62-83.

Liberman, R. P., Lillie, F., Falloon, I. R. H., Harpin, R. E., Hutchinson, W., \& Stoute, B. (1984). Social skills training with relapsing schizophrenics. Behavior Modification, 8, 155-179.

Presly, A. S., Grubb, A. B., \& Semple, D. (1982). Predictors of successful rehabilitation in long-stay patients. Acta Psychiatrica Scandinavica, 66, 83-88.

Ragia A. (2009). Mental health nursing. Athens, Greece: Elpinice Publications.

Rimm, D. C., Hill, G. A., Brown, N. N., \& Stuart, J. E. (1974). Group assertiveness training in treatment of expression of inappropriate anger. Psychological Reports, 34, 791-798.

Smith, T. E., Hull, J. W., MacKain, S. J., Wallace, C. J., Rattenni, L. A., Goodman, M. ... Kentros, M. K. (1996). Training hospitalized patients with schizophrenia in community reintegration skills. Psychiatric Services, 47, 1099-1103.

Sood, S., Baker, M., \& Bledin, K. (1996). Social and living skills of new long-stay hospital patients and new long-term community patients. Psychiatric Services, 47, 619-623.

Spence, A. J., \& Spence, S. H. (1980). Cognitive changes associated with social skills training. Behaviour Research and Therapy, 18, 265-272.

Sullivan, G., Marder, S. R., Liberman, R. P., Donahoe, C. P., \& Mintz, J. (1990). Social skills and relapse history in outpatient schizophrenics. Psychiatry, 53, 340-345.

Sylph, J. A., Ross, H. E., \& Kedwood, H. B. (1978). Social disability in chronic psychiatric patients. American Journal of Psychiatry, 134, 1390-1395.

Tsiantis, C., \& Manolopoulos, S. (1998). Current issues child psychiatry (3rd Volume, Chapter 9). Athens, Greece: Kastaniotis.

Wallace, C. J., \& Liberman, R. P. (1985). Social skills training for patients with schizophrenia. Psychiatry Research, 15, 239-247.

Wilkinson, J., \& Canter, W. (1991). Handbook of social skills training (K. Papaioannou \& E. Pappas, trans.). Thessaloniki, Greece: Publishing PS.N.TH. 